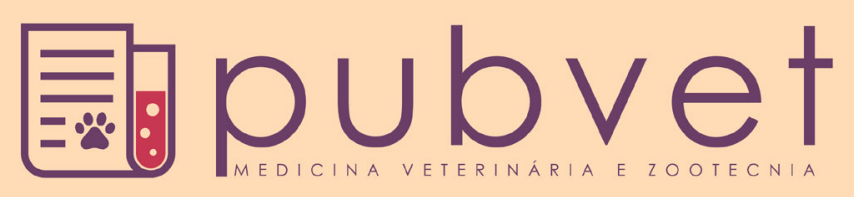

HTTP://DX.DOI.ORG/10.22256/PUBVET.V11N5.501-512

\title{
Adubação organomineral e NPK na cultura do milho (Zea mays $L_{.}$)
}

\author{
Carlos Arnaldo Alcântara Malaquiass, Alessandro José Marques Santos² \\ ${ }^{1}$ Engenheiro agrônomo, Universidade Estadual de Goiás - Campus Palmeiras de Goiás, Mestrando em Zootecnia, especializado em Manejo \\ e Conservação dos Ecossistemas Naturais e Sistemas Agrários. E-mail para contato: karlos eng.agronomo@hotmail.com \\ ${ }^{2}$ Pofessor Universidade Estadual de Goiás
}

RESUMO. Na atualidade é notável a evidente preocupação com nosso sistema produtivo em atender as premissas do desenvolvimento sustentável, atentando para o cumprimento dos pilares que o fundamentam sendo eles de cunho econômico, social e ambiental. Os fertilizantes organominerais são uma boa alternativa, sendo composto basicamente de uma mistura de fertilizantes minerais e orgânicos, que apresentam potencial de uso agrícola, pois tendem a ter um menor custo em relação aos fertilizantes químicos, e advém de resíduos de outros sistemas produtivos como por exemplo a cama de frango, viabilizando investimentos em seu uso e pesquisa muito por atender os ideais de conscientização crescente de uma produção, manejo e desenvolvimento rural sustentável. A utilização da matéria orgânica permite que se tenha uma racionalização do adubo mineral, promovendo um aumento da capacidade de troca catiônica $(\mathrm{T})$, reduzindo perdas por lixiviação e auxiliando na liberação dos nutrientes a planta, contribuindo para elevar a produtividade. Objetivou-se com este trabalho verificar parâmetros de produtividade em relação ao comportamento da utilização da adubação estritamente química e convencional contrapondo-se a adubação organomineral, visando desenvolvimento sustentável, fornecimento, solubilização e efeito residual de nutrientes no solo, reutilização de subprodutos e custos de produção.

Palavras chave: Composto, desenvolvimento, fertilização, solo, sustentabilidade

\section{Organomineral fertilization and NPK in corn (Zea mays $L$. .)}

ABSTRACT. At present, the obvious concern with our productive system is to attend to the premises of sustainable development, paying attention to the fulfillment of the pillars that base it being of an economic, social and environmental nature. Organomineral fertilizers are a good alternative, being basically composed of a mixture of mineral and organic fertilizers, which present potential for agricultural use, since they tend to have a lower cost in relation to chemical fertilizers, and comes from residues from other productive systems such as Such as the chicken litter, allowing investments in its use and research to meet the growing awareness of production, management and sustainable rural development. The use of organic matter allows for a rationalization of the mineral fertilizer, promoting an increase in the cation exchange capacity $(\mathrm{T})$, reducing leaching losses and aiding in the release of nutrients to the plant, contributing to increase productivity. The objective of this study was to verify productivity parameters in relation to the behavior of the use of strictly chemical and conventional fertilization, as opposed to organomineral fertilization, aiming at sustainable development, supply, solubilization and residual effect of nutrients in the soil, reuse of by-products and costs of production.

Keywords: Composting, development, fertility, soil, sustainability

Fertilización organomineral y NPK en el cultivo maíz (Zea mays L.) 
RESUMEN. Hoy en día es notable la preocupación con nuestro sistema de producción para atender las premisas del desarrollo sostenible, prestando atención al cumplimiento de los pilares que se basan en carácter económico, social y ambiental. Los fertilizantes organominerales son una buena alternativa, que se componen básicamente de una mezcla de fertilizantes minerales y orgánicos, que tienen uso potencial en la agricultura debido a que tienden a tener un costo menor en comparación con los fertilizantes químicos y proceden de residuos de otros sistemas de producción, tales como, la cama de pollo, viabilizando inversiones en su uso y pesquisa para satisfacer los ideales de conciencia creciente de una producción, gestión y desarrollo rural sostenible. El uso de materia orgánica permite que se tenga una racionalización del abono mineral, promoviendo un aumento en la capacidad de intercambio catiónico $(\mathrm{T})$, reduciendo pérdidas por lixiviación y ayudando en la liberación de nutrientes de la planta, contribuyendo para una mayor productividad. El objetivo de este trabajo fue verificar los parámetros de productividad en relación al comportamiento de la fertilización estrictamente química y convencional contraponiéndose la fertilización organomineral, objetivando de desarrollo sostenible, suministro, solubilización y efecto residual de nutrientes en el suelo, reutilización de subproductos y costo producción.

Palabras clave: Compostaje, desarrollo, abono, suelo, sostenibilidad

\section{Introdução}

Em dias contemporâneos, é notável a evidente preocupação com nosso sistema produtivo em atender as premissas do desenvolvimento sustentável, atentando para o cumprimento dos pilares que o fundamentam sendo eles de cunho econômico, social e ambiental.

O solo é um dos recursos naturais mais importantes para a qualidade de vida do homem, pois possui múltiplas funções nos ciclos dos nutrientes, no ciclo da água e também é importante para a sustentabilidade dos sistemas naturais, como as florestas primárias e campos, sendo um dos fatores mais relevantes na determinação da tipologia florestal (Silva et al., 2016).

Os fertilizantes organominerais são uma boa alternativa, sendo composto basicamente de uma mistura de fertilizantes minerais e orgânicos, que apresentam potencial de uso agrícola, pois tendem a ter um menor custo em relação aos fertilizantes químicos, e advém de resíduos de outros sistemas produtivos como por exemplo a cama de frango, viabilizando investimentos em seu uso e pesquisa muito por atender os ideais de conscientização crescente de uma produção, manejo e desenvolvimento rural sustentável. Os resíduos provenientes da criação intensiva de frangos, denominados de cama de frango, são ricos em nutrientes e, por estarem disponíveis nas propriedades a um baixo custo, podem ser viabilizados pelos produtores na adubação das culturas comerciais (Costa et al., 2009).

Sendo a cama de frango fonte de vários nutrientes, principalmente de $\mathrm{N}$, e com manejo correto, tem potencial para suprir parcial ou totalmente, o fertilizante químico. Além de sua utilização como fonte de nutrientes, o seu uso melhora teor de matéria orgânica que consequentemente beneficia os atributos físicos do solo, aumenta a capacidade de retenção de água, reduz a erosão, melhora a aeração e cria um ambiente mais favorável ao desenvolvimento da microbiota do solo.

De acordo com Bittencourt et al. (2006), a utilização da matéria orgânica permite que se tenha uma racionalização do adubo mineral, promovendo um aumento da capacidade de troca catiônica $(\mathrm{T})$, reduzindo perdas por lixiviação e auxiliando na liberação dos nutrientes a planta, contribuindo para elevar a produtividade. Todavia, regiões que apresentam característica de gerar grandes quantidades de resíduos orgânicos, deve-se atentar a utilização dos mesmos na adubação de pastagens e lavouras sem nenhum critério técnico, ou avaliação das necessidades do solo e das plantas nem tão pouco da composição química destes produtos (Berté et al., 2010).

Objetivou-se com este trabalho verificar parâmetros de produtividade em relação ao comportamento da utilização da adubação estritamente química e convencional contrapondose a adubação organomineral, visando desenvolvimento sustentável, fornecimento, solubilização e efeito residual de nutrientes no solo, reutilização de subprodutos e custos de produção, visando a diluição de custos para o produtor. 


\section{Adubação química nitrogenada na cultura do milho}

A cultura do milho é altamente exigente em fertilizantes químicos, principalmente os nitrogenados. Sendo que o suprimento inadequado de nitrogênio é considerado um dos principais fatores limitantes ao rendimento de grãos do milho, devido ao $\mathrm{N}$ exercer uma importante função nos processos bioquímicos da planta (Taiz and Zeiger, 2009). Já que são constituintes das proteínas, enzimas, coenzimas, ácidos nucleicos e clorofila (Santos et al., 2010).

A adubação nitrogenada, fundamentada em fertilizantes como nitrato de amônio, ureia agrícola e sulfato de amônio, apresenta empecilhos que reduzem a potencialidade de seu aproveitamento. $\mathrm{O}$ nitrogênio no solo pode ser perdido por processos como a volatilização da amônia, desnitrificação e lixiviação do nitrato. As perdas de nitrogênio aplicado na forma de ureia podem variar de 40 a $78 \%$ quando aplicada na superfície de solos cultivados com milho (Cabezas et al., 2000).

Dentre as práticas agronômicas, a adubação nitrogenada é considerada um dos principais fatores que influenciam na produtividade $\mathrm{e}$ também se relaciona com a qualidade dos grãos produzidos. O nitrogênio é de grande importância para grande maioria das culturas, pela sua participação na constituição de substâncias determinantes da qualidade do grão, uma vez que parte do nitrogênio $(\mathrm{N})$ é destinado a formação das proteínas constituintes do glúten, presente nos grãos dos cereais (Fageria et al., 2006).

A maior parte do $\mathrm{N}$ usado para sintetizar proteína no grão é absorvida até a floração, assim, a quantidade de $\mathrm{N}$ armazenado nos tecidos da planta no momento da floração é que define o $\mathrm{N}$ disponível para sintetizar compostos nitrogenados na planta e para a formação de proteína nos grãos (Mendes et al., 2012). Sendo assim, a adubação nitrogenada no florescimento aumenta a disponibilidade de $\mathrm{N}$, justamente, antes do enchimento de grãos, permitindo que maiores quantidades de proteínas sejam sintetizadas possibilitando uma melhoria na qualidade dos grãos (Gutkoski et al., 2002, Pinnow et al., 2013).

$\mathrm{O}$ nitrogênio $(\mathrm{N})$ é um elemento que apresenta grande dinâmica no sistema solo-plantaatmosfera, é perdido facilmente por volatilização ou lixiviação, além de os adubos nitrogenados terem baixa eficiência apresentam alto custo de sinterização, o que permite considerar que sua utilização sem critério, onera e muito os custos de produção, além de contaminar o ambiente, já que a acentuada disponibilidade de $\mathrm{N}$ pode resultar no alongamento da fase vegetativa das culturas, o que acarreta perdas significativas no potencial produtivo (Santos et al., 2016). De acordo com Duete et al. (2009) para que se tenha uma melhor eficiência da aplicação de $\mathrm{N}$, indica-se $\mathrm{o}$ parcelamento da adubação nitrogenada. Tendo este o objetivo de minimizar as perdas por lixiviação, sendo que menor quantidade de nitrogênio ficará sujeita a lixiviação, o que evita perdas. No entanto por outro lado, a adubação parcelada exige mão de obra e tempo, o que tende a elevar custos de produção.

Freire et al. (2010) enfatizam que as perdas de $\mathrm{N}$ que ocorrem devido à volatilização podem reduzir a eficiência da adubação nitrogenada. Complementando a ideia Souza and Soratto (2006) dizem que especialmente quando a fonte de $\mathrm{N}$ é a ureia, sua perda pode ser maior que o sulfato de amônio, principalmente em épocas de precipitação irregular. $\mathrm{O}$ adequado manejo da adubação nitrogenada beneficia o ambiente por causar menores níveis de acidificação do solo, eutrofização das águas, poluição do lençol freático e salinização de áreas (Bittencourt, 2009).

Estendendo este benefício a vários segmentos da cadeia produtiva, indo do produtor, atingindo maiores índices de produtividade e margem de lucro, passando pelos agentes técnicos alcançando boas vendas de insumos e, chegando, aos consumidores beneficiados pelas melhores características sensoriais dos produtos e, consequentemente, tendo condições de competir por um menor preço de compra, adquirindo um produto de alta qualidade (Santos et al., 2016).

A amônia (N-NH3) perdida por volatilização pode ser proveniente da mineralização da matéria orgânica ou do fertilizante aplicado, sendo esse o fenômeno mais intenso mediante aumento do $\mathrm{pH}$ do solo. Essa intensificação do processo de perda de $\mathrm{N}$ pode ocorrer nos estágios reprodutivos, onde há aumento do potencial de volatilização de $\mathrm{N}-$ $\mathrm{NH} 3$ devido as mudanças no metabolismo do $\mathrm{N}$ da planta, e também por meio da quebra de proteínas e aminoácidos (Bologna et al., 2006).

Deste modo é preciso atentar-se para este tipo de perda, pois pode chegar a $80 \%$ do adubo aplicado, ou seja, em casos extremos a planta consegue utilizar apenas $20 \%$ do $\mathrm{N}$ proveniente do fertilizante. Essas perdas precisam ser bem 
compreendidas para orientação do adequado manejo de adubação, visando melhorar o aproveitamento dos fertilizantes aplicados.

\section{Adubação química fosfatada na cultura do milho}

Almeida et al. (2016) afirmam que o fósforo (P) é um elemento de grande importância, participando de vários processos metabólicos nas plantas. Segundo os mesmos, sua interação com constituintes do solo, como alumínio (Al), ferro $(\mathrm{Fe})$ e cálcio $(\mathrm{Ca})$, aliado com a sua ocorrência em formas orgânicas e a sua lenta taxa de difusão na solução do solo o torna menos disponível na rizosfera.

Para adequada nutrição das culturas instaladas em solos do Cerrado brasileiro, se faz necessária a utilização de elevadas doses de fertilizantes, devido ao predomínio de solos altamente intemperizados, caracterizados pela baixa disponibilidade de nutrientes as plantas. Deste modo, o fósforo $(\mathrm{P})$ merece especial atenção por causa da sua grande adsorção a fase mineral do solo, predominantemente de baixa reversibilidade, principalmente nos óxidos de $\mathrm{Fe}$ e $\mathrm{Al}$ (Schoninger et al., 2013). Teores de P na solução dos solos da região do Cerrado são geralmente muito baixos. E apresentam esta característica, por estarem associada a alta capacidade que esses solos têm para reter o $\mathrm{P}$ na fase sólida, é a principal limitação para o desenvolvimento de qualquer atividade agrícola rentável sem a aplicação de adubos fosfatados (Wietholter et al., 1994). Todavia, em sistema de semeadura direto há maior eficiência de aproveitamento do $\mathrm{P}$ pelas plantas, sendo isso atribuído ao menor contato entre fertilizante e partículas do solo, promovido pela ausência de revolvimento e a presença de resíduos vegetais, ou palhada sob a superfície do solo que favorece a retenção de umidade (Rosim et al., 2012). Segundo Camêlo et al. (2015) o que melhora a taxa de difusão do fósforo até as raízes, sendo que em solos de clima tropical, acredita-se que os ácidos orgânicos competem pelos sítios de adsorção de $\mathrm{P}$, podendo aumentar a sua disponibilidade devido ao recobrimento dos óxidos de Fe e de Al. No entanto, Almeida et al. (2016) afirmam que vale ressaltar que, neste caso, a presença de matéria orgânica reduz a adsorção de P., sendo essas reduções mesmo que em pequenas proporções, podem aumentar a eficiência agronômica dos fertilizantes fosfatados em solos altamente intemperizados, possibilitando maior absorção de P pelas culturas. É sabido que as fontes de elevada solubilidade apresentam maior eficiência em menor espaço de tempo em relação aos fosfatos naturais. No entanto, os solos tropicais, com elevada capacidade de adsorção de $\mathrm{P}$, o nutriente oriundo da fonte solúvel é rapidamente convertido a formas menos disponíveis reduzindo assim sua eficiência (Lourenzi et al., 2014). Este elemento desempenha um importante papel nas plantas, uma vez que está fortemente ligado a inúmeros processos metabólicos, atuando também na constituição do ATP, do DNA e de enzimas, como a fosforilase. Visto que o principal papel do $\mathrm{P}$ na fisiologia da planta, é fornecer energia para reações biossintéticas e para o metabolismo vegetal (Fabrice et al., 2015, Sfredo, 2008). O fósforo é absorvido na forma iônica como $\mathrm{H}_{2} \mathrm{PO}_{4}^{-}$, sendo que esta é a forma predominante na faixa de $\mathrm{pH}$ 4,0 a 8,0 , na qual vivem a maioria das plantas (Sfredo, 2008). Este elemento é responsável também pelo bom desenvolvimento das raízes e de plântulas no início do seu desenvolvimento, contribuindo para o aumento da resistência, na melhoria do uso da água, na resistência as doenças, sendo importante para a colheita e qualidade das culturas (Malavolta, 2006).

Alcântara Neto et al. (2010) citam que dentre os macros nutrientes essenciais as plantas, o fósforo é o elemento que limita com maior frequência a produção das culturas na região dos cerrados. Estes ainda citam sem o fósforo, a produtividade da cultura da soja dentre outras é baixa, ocorrendo ainda redução no porte da planta e na altura de inserção das primeiras vagens.

Por outro lado, um efetivo suprimento de fósforo para a planta promove incrementos significativos na produção, em áreas de cerrado, mesmo no primeiro ano de cultivo. No entanto, em solos com mais de três anos de cultivo, com adubações as plantas apresentam pouca resposta a adubação fosfatada devida ao efeito residual presente no solo, principalmente para soja que possui habilidade para aproveitar o efeito residual das fertilizações de anos anteriores (Sfredo, 2008).

Levando em consideração a necessidade de se calibrar uma dose eficiente e econômica de fósforo a ser aplicada e que as reservas de rochas fosfatadas no país são escassas, e aliado aos altos custos de importação deste fertilizante, e também ao fato de que o nutriente é um recurso não renovável, justificam-se estudos para otimizar a eficiência no uso de fertilizantes fosfatados (Prochnow et al., 2003). 


\section{Adubação química potássica na cultura do milho}

De acordo com Parente et al. (2016), o potássio (K) é o segundo nutriente mais absorvido pelas plantas sendo este essencial na ativação de várias enzimas que atuam nos processos de fotossíntese e respiração. O potássio é classificado como um macro nutriente essencial para as plantas. Neste contexto, alguns fatores podem diminuir sua disponibilidade, como a falta de reposição por meio de programas de adubação e o manejo inadequado das adubações realizadas, podendo levar a indisponibilidade para as plantas pelo processo de lixiviação (Garcia et al., 2015). Em solos tropicais, os teores de $\mathrm{K}^{+}$normalmente encontrados são considerados baixos $(<1,5$ mmolc $\mathrm{dm}^{-3}$ ), sendo necessária a utilização de fertilizantes potássicos para complementação (Prochnow et al., 2003). Visto que sua deficiência pode acarretar diminuição dos internódios, redução na dominância apical e no crescimento das plantas, e retardar a frutificação, originando frutos menores e com coloração menos acentuada (Ernani et al., 2008).

Os atributos químicos que mais afetam a lixiviação são a capacidade de troca de cátions $(\mathrm{T})$ e o $\mathrm{pH}$, visto que solos com alta (T) apresentam maior capacidade de adsorção dos cátions, sendo menos suscetíveis à lixiviação. Com o aumento do $\mathrm{pH}$, a (T) do solo se eleva e, consequentemente, os cátions disporão de maior número de cargas para adsorção (Santos et al., 2002). Segundo um estudo conduzido por Rosolem et al. (2006) a respeito da dinâmica do potássio no solo, verificou-se um aumento na lixiviação de $\mathrm{K}$ no perfil de um solo de textura média, quando se utilizou a aplicação de doses acima de $80 \mathrm{~kg} \mathrm{ha}^{-1}$ de $\mathrm{K}_{2} \mathrm{O}$ por ano, independentemente do modo utilizado na aplicação do mesmo.

Uma maneira de se tentar minimizar os efeitos da lixiviação do elemento $\mathrm{K}$ no solo, seria a sua quelatização com componentes químicos, porém tal tecnologia onera de forma significativa o custo do insumo, ou uma associação com a matéria orgânica, devido à grande $(\mathrm{T})$ dos radicais carboxílicos presentes no material orgânico. Associando-se os benefícios da adubação mineral, devido apresentar alta solubilidade dos nutrientes aos benefícios da matéria orgânica, devido a melhoria das características físico-químicas do solo temos a adubação organomineral (Garcia et al., 2015). Todavia, em relação as perdas por lixiviação, é importante lembrar que elas diminuem quando a área é cultivada em sistema de plantio direto, que favorece o acúmulo nas camadas mais superficiais do solo (Parente et al., 2016).

Ferreira et al. (2011) afirmam que a disponibilidade de nutrientes para as plantas em sistemas de produção depende da fertilidade do solo e da velocidade de degradação dos resíduos, sendo que, em cultivos intensivos, o $\mathrm{K}$ absorvido pelas plantas permanece a maior parte do tempo no tecido vegetal, não sofrendo erosão ou lixiviação. Sendo assim, as variáveis climáticas, como temperatura e umidade local, afetam a velocidade de liberação do $\mathrm{K}$ para o solo. Os mesmos autores corroboram que, embora a quantidade absorvida desse nutriente seja elevada, apenas $20 \%$ em média é exportado pelos grãos, o restante retorna ao solo pela decomposição da matéria orgânica.

Para Veiga et al. (2010) o K apresenta grande importância na nutrição mineral da cultura da soja, pois participa na formação de nódulos e aumenta o teor de óleo. Sendo assim, a aplicação de K em maiores quantidades no cultivo do milho pode favorecer a cultura da soja em sucessão, a ponto de reduzir a necessidade desse nutriente via fertilizante mineral, sendo esta prática benéfica para ambas às culturas.

\section{Compostagem}

A etimologia da palavra composto é originada do latim compositu, que significa um complexo ou aglomerado de vários elementos juntos (Diniz Filho et al. (2007). Compostagem é uma alternativa de reciclagem de resíduos, o que resulta na produção de um adubo acessível, visando a produção de pequenos agricultores pela minimização, e/ou uso racional do uso de adubos industrializados (Costa and Silva, 2011). A partir da mesma é produzido o composto orgânico, que é um produto rico em nutrientes, podendo ser utilizado no manejo da adubação. Sendo normal o desenvolvimento das culturas, ficando dependente da realização de uma adubação equilibrada e da aplicação de corretivos de acidez, apenas quando se faz necessário (Castro et al., 2015).

Segundo Kiehl (2004), a compostagem é um processo controlado de decomposição microbiana de oxidação e oxigenação de uma massa heterogênea de matéria orgânica no estado sólido e úmido. Ainda segundo esse autor, sua finalidade é obter rapidamente e em melhores condições a estabilização da matéria orgânica, no processo da 
compostagem, sendo que os restos orgânicos são amontoados, preferencialmente revolvidos, e assim se decompõem em menor tempo, produzindo um melhor adubo orgânico.

A compostagem é utilizada em resíduos sólidos provenientes de diversas fontes orgânicas. Entretanto, os resíduos líquidos também podem ser passíveis desta tecnologia, sendo que para isso há necessidade de alterar suas características físicas, através de agentes de estruturação, como cama de frango, casca de arroz ou serragem.

O sistema apresenta características e processos similares independentemente do método de compostagem a ser utilizado, caracterizando-se por uma sucessão de diferentes populações de microrganismos aeróbios que colonizam a biomassa, produzindo calor e desprendimento de $\mathrm{CO}_{2}$ (Liu et al., 2011). Altas temperaturas e liberação de $\mathrm{CO}_{2}$ estão relacionadas ao metabolismo exotérmico e a respiração dos microrganismos que colonizaram a massa em compostagem, sendo estes responsáveis pela maior parte das modificações físico-químicas na biomassa, determinando assim a fase em que se encontra a compostagem (Bernal et al., 2009). Em relação aos adubos químicos em se tratando de custos de produção, a compostagem reduzem de três a quatro vezes os custos, portanto se caracterizando muito rentável, além de ser uma prática sustentável (Diniz Filho et al., 2007).

Advindo das preocupações sobre saúde pública e alimentos de qualidade e segurança alimentar. A conservação do meio ambiente e práticas conservacionistas têm sido levadas em consideração diante de um crescente interesse em práticas agrícolas alternativas com menor quantidade de produtos químicos sintéticos e maior dependência de processos biológicos naturais. A agricultura orgânica pode aumentar a biodiversidade do solo, aliviar preocupações ambientais e melhorar a segurança alimentar por meio da eliminação das aplicações de produtos químicos sintéticos ( $\mathrm{Tu}$ et al., 2006). Várias técnicas têm sido utilizadas no intuito de eliminação, tanto quanto para a utilização vantajosa de adubos. Dentre os exemplos estão a aplicação de fertilizantes, gás metano (biogás) a produção, a evaporação, NH3 produção, separação de sólidos, hidrólise, hidrogenação, compostagem, realimentação animal e o uso como substrato de plantas e síntese de proteína microbiana (Mikkelsen, 2000).
A produção convencional enfoca a sustentabilidade econômica, alcançada por meio da adição constante de insumos dos mais variados tipos ao sistema produtivo. Porém o diferencial na produção orgânica é que a sustentabilidade enfatiza de modo singular a integração das dimensões sociais, econômicas e ambientais. Visando suas práticas partirem de uma concepção que considera o contexto socioeconômico e cultural das pessoas envolvidas na produção, além do respeito ao direito da população de consumir alimentos saudáveis (Stringheta, 2003). Parafraseando Finatto et al. (2014) afirmam que a utilização de adubo orgânico beneficia a agricultura de modo geral, apresenta potencial de resposta produtiva, é uma opção de custo inferior para aquisição de produtos desta linha. Protege e conserva o ambiente, preservando os recursos naturais.

\section{Adubação orgânica}

Os adubos orgânicos têm ganhado sido alvo de amplas discussões entre vários autores como sendo uma alternativa para diminuir o custo energético das lavouras, proporcionando economia de recursos naturais. A utilização de cobertura morta no solo é uma prática amplamente recomendada, em particular em regiões semiáridas, pois contribui para a melhoria do desempenho das culturas e aumento na retenção de umidade do solo (Souza et al., 2011). Montenegro et al. (2013) constataram a grande importância da cobertura morta em relação a manutenção da umidade do solo, e controle de perdas de solo. Diferentemente da adubação mineral, a orgânica apresenta uma dinâmica diferenciada no solo. Como por exemplo o fato do $\mathrm{N}$ que é um nutriente muito exigido pelas culturas, que quando fornecido através da adubação mineral, praticamente não deixa residual, ao contrário, de quando é aplicado via adubação orgânica. Um dos grandes desafios na busca da sustentabilidade da agricultura está na adubação, que dependente de fontes minerais não renováveis para o fornecimento de elementos essenciais, tais como Nitrogênio, Fósforo e Potássio, enfatizandose que, para a obtenção de fertilizantes nitrogenados, os gastos com energia fóssil são muito altos. No entanto, nas últimas décadas, vêm sendo utilizadas e estudadas como alternativa econômica e ambiental, fontes orgânicas em cultivos agrícolas, em substituição parcial ou total de fertilizantes minerais. Sendo, uma das possibilidades para se reduzir o emprego de 
insumos sintéticos aos solos e as plantas é a utilização de esterco líquido, como os biofertilizantes (Cavalcante et al., 2007). Utilizar compostos orgânicos vem ganhando espaço como alternativa de adubação do solo e nutrição de plantas em substituição aos adubos minerais convencionais, pois os adubos orgânicos, quando utilizados isolados ou associados a adubos minerais, revelam propriedades altamente benéficas ao solo, como fornecimento de nutrientes, retenção de umidade, ativação da microbiota do solo, melhoria da textura e estrutura dentre outras.

Os biofertilizantes são um adubo orgânico líquido produzido em meio aeróbico ou anaeróbico a partir de uma mistura de material orgânico (esterco fresco) e água (PENTEADO, 2007). De acordo com SILVA e MENDONÇA (2007), a aplicabilidade de produtos orgânicos na agricultura é importante por conta da diversidade dos nutrientes minerais e pela ação positiva de ativador enzimático do metabolismo vegetal. Entretanto, Peña et al. (2005) afirmam que a participação da biota do solo no funcionamento e sustentabilidade dos ecossistemas é muito conhecida e difundida. Sendo que, alguns parâmetros referentes a atividade dos microrganismos no solo podem ser utilizados como bioindicadores para avaliação do estado de equilíbrio ou desequilíbrio de ecossistemas florestais. Santos and Camargo (1999) relatam que um grande desafio da ciência do solo é mostrar a relação entre níveis de atividade biológica e o funcionamento sustentável dos ecossistemas. A biomassa microbiana do solo é um componente importante da matéria orgânica do solo. Por regular as transformações microbiológicas e acúmulo de nutrientes (Mendonça and Matos, 2005). A disponibilidade de matéria orgânica e a qualidade dos resíduos adicionados ao solo influenciam a concentração e atividade dos microrganismos responsáveis por converter a matéria orgânica crua biodegradável para o estado de matéria prima orgânica umidificada, processo esse que libera $\mathrm{CO}_{2}$ (Severino et al., 2004). Então fazer uso de adubos orgânicos, de maneira geral, é favorável a manutenção da matéria orgânica do solo, melhorando suas propriedades físicas, químicas e biológicas. A matéria orgânica auxilia a atividade dos organismos do solo, que por sua vez resulta em impactos positivos sobre a ciclagem de nutrientes (Alves, 2008). Do ponto de vista físico, o uso de adubos orgânicos promove o aumento da estabilidade de agregados, associado à redução da densidade do solo (Geremias et al., 2015). Visto que a macrofauna do solo, apresenta um importante papel nos processos do ecossistema no que se refere a ciclagem de nutrientes e estrutura do solo, pois é responsável pela fragmentação dos resíduos orgânicos, mistura das partículas minerais e orgânicas, redistribuição da matéria orgânica (Baretta et al., 2011).

Existem diferentes formas de monitorar a qualidade do solo, dentre elas destaca-se o uso de indicadores biológicos, especialmente na avaliação da fauna edáfica (Pereira et al., 2013). Sendo que os organismos edáficos possuem a capacidade de apresentar resposta rápida as mudanças na qualidade do solo, característica que não é observada nos indicadores físico-químicos. No entanto em alguns casos, alterações na abundância, diversidade e na atividade de organismos edáficos, incluindo microrganismos, podem indicar mudanças nas propriedades físicas e químicas, refletindo um claro sinal na melhoria ou degradação da qualidade do solo (Vasconcellos, 1977). Neste contexto, a adição de resíduos orgânicos é um fator que pode influenciar a biota do solo, principalmente pelo fornecimento de alimento para os organismos edáficos (Geremias et al., 2015). Alves (2008) constataram em seus resultados efeito negativo sobre a abundância da macrofauna edáfica na presença de adubação mineral e, um efeito benéfico nos tratamentos que receberam fertilizante mineral e orgânico. Deixando notável que a adubação orgânica evidencia e favorece o desenvolvimento dos organismos do solo, pois devido ao maior aporte de material orgânico no sistema promove um efeito benéfico sobre os grupos mais frequentes da fauna de solo (Baretta et al., 2011).

\section{Adubação organomineral na cultura do milho}

A crescente necessidade de fornecer nutrientes as plantas, leva em consideração os custos de produção do ciclo da cultura, o aumento da demanda na produção de alimentos e os problemas ambientais que a sociedade atual vem enfrentando, faz com que as pesquisas no setor agrícola se desenvolvam de forma acentuada (Chiconato et al., 2013). O reaproveitamento de adubos orgânicos de origem animal é de fundamental importância para o desenvolvimento e crescimento de culturas exploradas. Juntamente associado, está o baixo custo dos adubos orgânicos e a melhoria e conservação do solo (Pauletti et al., 2008). O rebanho aviário gera 7,8 milhões de toneladas de cama. Esses resíduos somados 
contêm cerca de 680.000 toneladas de N, 660.000 toneladas de $\mathrm{P}^{2} \mathrm{O}^{5}$ e 440.000 toneladas de $\mathrm{K}^{2} \mathrm{O}$, o que representam aproximadamente $27 \%, 21 \%$ e $12 \%$ do total anual consumido de N, P e K pela agricultura brasileira, respectivamente.

A utilização de resíduos orgânicos como cama de frango em culturas locais é uma alternativa viável, considerando a alta produção de matériaprima na região Centro-Oeste brasileira, que tem se destacado como a nova fronteira para a produção de frangos de corte no Brasil (França et al., 2009). Contribuindo Menezes et al. (2003) afirmam que este setor trouxe novas possibilidades de aproveitamento da cama de frango como fonte de nutrientes para a agricultura. As principais dúvidas sobre o uso dos organominerais são relacionadas com a sua eficiência agronômica, seu efeito no solo e seu custo, em comparação com fontes convencionais de nutrientes (Wietholter et al., 1994).

A utilização de biofertilizantes tem-se difundido bastante atualmente, visto que são notáveis os elevados custos dos adubos minerais e os efeitos benéficos que a matéria orgânica proporciona aos solos. A matéria orgânica fornecida a partir de esterco animal e composta orgânicos melhora as características físicas e químicas do solo, além de reduzir a utilização de adubos químicos (Galbiatti, 1992). De acordo com Penteado (2007) biofertilizantes são adubos vivos, pois são constituídos de microrganismos, sendo um adubo orgânico que pode ser liquido ou solido resultante de um processo de decomposição da matéria orgânica, seja ela animal ou vegetal, pela fermentação microbiana, com ou sem a presença de oxigênio, ocorrida em meio liquido. Haja visto que no que se refere a matéria orgânica, esta apresenta uma série de benefícios para a fertilidade do solo e, evidentemente, para as plantas cultivadas, porque pode reduzir a acidez, diminuir os teores de alumínio e manganês tóxicos, e elevar o $\mathrm{pH}, \mathrm{CTC}$, transporte e disponibilidade de micronutrientes, melhora na estrutura do solo, refletindo de forma positiva na aeração, permeabilidade e infiltração de água, promovendo um desenvolvimento vegetativo adequado e proporcionando produtividades economicamente viáveis (Cardoso and Oliveira, 2002). Dito isto, Ourives et al. (2010) verificaram em seus estudos os efeitos da matéria orgânica na disponibilidade de fósforo, notando a elevação nos teores de fósforo disponível devido a associação da matéria orgânica com a adubação química convencional.
Segundo Santos et al. (2011), fontes orgânicas tem capacidade de substituir parte, ou até mesmo todo o fósforo exigido pelas plantas, alterando os atributos químicos do solo, elevando a disponibilidade de cálcio, nitrogênio, fósforo, além dos teores de carbono orgânico. O composto orgânico quando adicionado a fosfato de rocha leva a criação de um ambiente propício para determinadas reações bioquímicas. Como consequência há redução das emissões totais de $\mathrm{CO}_{2}$ por ocorrer formação de carbonato de cálcio na sequência das reações metabólicas, que são encontradas na decomposição da matéria orgânica e digestão da rocha fosfática. A glicose resultante do metabolismo dos microrganismos decompositores combinada com o oxigênio forma o gás carbônico e a água. Este gás carbônico reage com o fosfato tricálcico e forma o fosfato dicálcico, que na presença de excesso de $\mathrm{CO}_{2}$ e catalisador biológico, reage formando o fosfato monocálcico, que é solúvel e assimilável pelas plantas.

A compostagem na sua forma ideal de utilização se caracteriza por um processo biológico, aeróbio e termófilo, controlado e manejado, de degradação de sólidos orgânicos, que tem por resultado final um produto orgânico estável, química e biologicamente, para uso agricultura como insumo (Epstein, 1975). Segundo Kiehl (2004), o produto orgânico pode ser obtido pelas fontes de materiais, entre os mais utilizados para o processo de compostagem estão os resíduos de cereais, turfa e excrementos de animais. Resíduos animais são ricos em elementos essenciais para a nutrição das plantas, justificando o uso como fertilizante orgânico. Os resíduos aviários possuem maior reserva de nutrientes se comparados a dejetos de outros animais, pois são obtidos através da mistura de fezes e grande oferta de ração no sistema de criação intensiva.

\section{Considerações finais}

Acredita-se que com a utilização de subprodutos ou resíduos orgânicos combinados a adubação mineral, gerando os fertilizantes organominerais apresentam um ótimo potencial de uso agrícola, como adubos de fontes alternativas em culturas anuais e perenes como por exemplo: cultivos comerciais de grande valor agregado como as commodities milho, soja, feijão, trigo, algodão e cultivos perenes de grande relevância como pastagens. 
A utilização dos organominerais apresentam características físicas, químicas e biológicas benéficas, fornecendo matéria orgânica ao solo, melhorando fertilidade, estrutura, aeração e retenção de água no mesmo.

Pensando na vertente da produção e desenvolvimento sustentável é factível e economicamente viável transformar resíduos e rejeitos orgânicos de agente da condição de poluidores em produtos condicionadores dos aspectos físicos do solo e fornecendo nutrientes as plantas, visando a redução no uso de fertilizantes minerais, contribuindo com a conservação ambiental.

\section{Referências Bibliográficas}

Alcântara Neto, F., Amaral Gravina, G., Souza, N. O. S. \& Carvalho Bezerra, A. A. 2010. Adubação fosfatada na cultura da soja na microrregião do Alto Médio Gurguéia. Revista Ciência Agronômica, 41, 266-271.

Almeida, T., Pocojeski, E., Nesi, C. N., Silva, L. S. \& Oliveira, J. P. M. 2016. Eficiência de fertilizante fosfatado protegido na cultura do milho. Scientia Agraria, 17, 29-35.

Alves, A. U. 2008. Fotes e parcelamento de nitrogênio na produção de batata-doce. Fitotecnia. Universsidade Federal da Paraíba, Areia.

Baretta, D., Santos, J. C. P., Segat, J. C., Geremia, E. V., Oliveira Filho, L. C. I. \& Alves, M. V. 2011. Fauna edáfica e qualidade do solo. Tópicos em Ciência do Solo. Viçosa: Sociedade Brasileira de Ciência do Solo, 7, 119-170.

Bernal, M. P., Alburquerque, J. A. \& Moral, R. 2009. Composting of animal manures and chemical criteria for compost maturity assessment. A review. Bioresource Technology, 100, 5444-5453.

Berté, L. N., Castagnara, D. D., Bulegon, L. G., Kuhl, J. A., Eninger, E. M., Santos, L. B., Vendrame, J. P., Oliveira, P. S. R. \& Neres, M. A. 2010. Associação da adubação química e orgânica na produção de milho para silagem no Oeste do Paraná. $28^{a}$ Congresso Nacional de Milho e Sorgo, Goiânia. UNIOESTE, Goiânia, Goiás.

Bittencourt, M. V. L. 2009. Impactos da agricultura no meio-ambiente: Principais tendências e desafios (Parte 1). Revista Economia \& Tecnologia, 5.
Bittencourt, V. C., Strini, A. C., Cesarim, L. G. \& Souza, S. R. 2006. Torta de filtro enriquecida. Revista Idea News, 6, 2-6.

Bologna, I. R., Faroni, C. E., Lange, A. \& Trivelin, P. C. 2006. Perda de nitrogênio pela parte aérea de plantas de trigo. Ciência Rural, 36, 11061111.

Cabezas, W. A. R., Trivelin, P. C. O., Kondörfer, G. H. \& Pereira, S. 2000. Balanço da adubação nitrogenada sólida e fluida de cobertura na cultura de milho, em sistema plantio direto no Triângulo Mineiro (MG). Revista Brasileira de Ciência do Solo, 24, 363-376.

Camêlo, D. d. L., Ker, J. C., Novais, R. F., Corrêa, M. M. \& Lima, V. C. 2015. Sequential extraction of Phosphorus by ,ehlich-1 and ion exchange resin from $b$ horizons, $S$ of ferric and perferric latosols (oxisols). Revista Brasileira de Ciência do Solo, 39, 1058-1067.

Cardoso, E. L. \& Oliveira, H. 2002. Sugestões de uso e manejo dos solos do Assentamento Taquaral, Corumbá-MS. Embrapa Pantanal. Circular Técnica, 1, 1-4.

Castro, R. S., Santos, P. M. \& Almeida, H. D. 2015. Influência de compostos orgânicos não estabilizados sobre a acidez do solo. Cadernos de Agroecologia, 10, 1-5.

Cavalcante, L. F., Santos, G. D., Oliveira, F. A., Cavalcante, İ. H. L., Gondim, S. C. \& Cavalcante, M. Z. B. 2007. Crescimento e produção do maracujazeiro-amarelo em solo de baixa fertilidade tratado com biofertilizantes líquidos. Revista Brasileira de Ciências Agrárias, 2, 15-19.

Chiconato, D. A., De Simoni, F., Galbiatti, J. A., Franco, C. F. \& Caramelo, A. D. 2013. Resposta da alface à aplicação de biofertilizante sob dois níveis de irrigação. Bioscience Journal, 29, 392-399.

Costa, A. M., Borges, E. N., Silva, A. A., Nolla, A. \& Guimarães, E. C. 2009. Potencial de recuperação física de um Latossolo Vermelho, sob pastagem degradada, influenciado pela aplicação de cama de frango. Ciência $e$ Agrotecnologia, 33, 1991-1998.

Costa, A. P. \& Silva, W. C. M. 2011. A compostagem como recurso metodológico para o ensino de ciências naturais e geografia no ensino fundamental. Enciclopédia Biosfera, 7, 1-12.

Diniz Filho, E. T., Mesquita, L. d., Oliveira, A. d., Nunes, C. G. F. \& Lira, J. F. B. 2007. A prática 
da compostagem no manejo sustentável de solos. Revista Verde de Agroecologia e Desenvolvimento Sustentável, 2, 27-36.

Duete, R. R. C., Muraoka, T., Silva, E. C., Ambrosano, E. J. \& Trivelin, P. C. O. 2009. Acúmulo de nitrogênio $(15 \mathrm{~N})$ pelos grãos de milho em função da fonte nitrogenada em Latossolo Vermelho. Bragantia, 68, 463-472.

Epstein, E. 1975. Nutrição mineral das plantas; princípios e perspectivas, tradução. Livros Técnicos e Científicos, Rio de Janeiro.

Ernani, P. R., Almeida, J. A. \& Santos, F. C. 2008. Otimização da adubação em lavoura com altos tepres de potássio no solo: Uso da agricultura de precisão. II Simposóio Internacional Savanas Tropicais. Brasília, Brasil.

Fabrice, C. E. S., Soares Filho, C. V., Pinto, M. F., Perri, S. H. V., Cecato, U. \& Mateus, G. P. 2015. Recuperação de pastagens de" Brachiaria decumbens" degradada com introdução de Stylosanthes e adubação fosfatada. Revista Brasileira de Saúde e Produção Animal, 16, 758-771.

Fageria, N. K., Baligar, V. C. \& Clark, R. 2006. Physiology of crop production. Haworth Press, New York, USA.

Ferreira, E. V. O., Anghinoni, I., Andrighetti, M. H., Martins, A. P. \& Carvalho, P. C. F. 2011. Ciclagem e balanço de potássio e produtividade de soja na integração lavourapecuária sob semeadura direta. Revista Brasileira de Ciencia do Solo, 35, 161-169.

Finatto, J., Altmayer, T., Martini, M. C., Rodrigues, M., Basso, V. \& Hoehne, L. 2014. A importância da utilização da adubação orgânica na agricultura. Revista Destaques Acadêmicos, 5, 85-93.

França, C. G., Del Grossi, M. E. \& Marques, V. P. M. 2009. El censo agropecuario 2006 y la agricultura familiar en Brasil. Brasília.

Freire, F. M., Viana, M. C. M., Mascarenhas, M. H. T., Pedrosa, M. W., Coelho, A. M. \& Andrade, C. L. T. 2010. Produtividade econômica e componentes da produção de espigas verdes de milho em função da adubação nitrogenada. Revista Brasileira de Milho e Sorgo, 9, 213-222.

Galbiatti, J. A. 1992. Efeito do uso contínuo de efluente de biodigestos sobre algumas características físicas do solo e o comportamento do milho (Zea Mays L.). 1992. 212 f. Faculdade de Ciências Agrárias e
Veterinárias. Universidade Estadual Paulista, Jaboticabal.

Garcia, J. C., Boneti, J. E. B., Azania, C. A. M., Belucci, L. R. \& Vitorino, R. 2015. Fontes de adubação potássica na lixiviação de potássio em neossolo quartzarênico. Revista Eletrônica Thesis, 24, 76-89.

Geremias, E. V., Segat, J. C., Fachini, I. A., Fonseca, E. O. \& Baretta, D. 2015. Fauna edáfica em pastagem perene sob diferentes fontes de nutrientes. Scientia Agraria, 16.

Gutkoski, L. C., Rosa Filho, O. \& Trombetta, C. 2002. Correlação entre o teor de proteínas em grãos de trigo e a qualidade industrial das farinhas. Boletim do Centro de Pesquisa de Processamento de Alimentos, 20, 29-40.

Kiehl, E. J. 2004. Manual de compostagem: maturação e qualidade do composto. Degaspari, Piracicaba.

Liu, D., Zhang, R., Wu, H., Xu, D., Tang, Z., Yu, G., Xu, Z. \& Shen, Q. 2011. Changes in biochemical and microbiological parameters during the period of rapid composting of dairy manure with rice chaff. Bioresource Technology, 102, 9040-9049.

Lourenzi, C. R., Ceretta, C. A., Cerini, J. B., Ferreira, P. A. A., Lorensini, F., Girotto, E., Tiecher, T. L., Schapanski, D. E. \& Brunetto, G. 2014. Available content, surface runoff and leaching of phosphorus forms in a typic hapludalf treated with organic and mineral nutrient sources. Revista Brasileira de Ciência do Solo, 38, 544-556.

Malavolta, E. 2006. Manual de nutrição mineral de plantas. Agronômica Ceres, São Paulo.

Mendes, M. C., Rosário, J. G., Faria, M. V., Zocche, J. C. \& Walter, A. L. B. 2012. Avaliação da eficiência agronômica de Azospirillum brasilense na cultura do trigo e os efeitos na qualidade de farinha. Applied Research \& Agrotechnology, 4, 95-102.

Mendonça, E. S. \& Matos, E. S. 2005. Matéria orgânica do solo: métodos de análises. UFV, Viçosa, Minas Gerais.

Menezes, J. F. S., Alvarenga, R. C., Andrade, C. L. T., Konzen, E. A. \& Pimenta, F. F. 2003. Aproveitamento de resíduos orgânicos para a produção de grãos em sistema de plantio direto e avaliação do impacto ambiental. Revista Plantio Direto, 9, 30-35.

Mikkelsen, R. 2000. Beneficial use of swine byproducts: Opportunities for the future. In: 
Power, J. F. \& Dick, W. A. (eds.) Land Application of Agricultural, Industrial and Municipal by-Products. Soil Science Society of America, Madison, USA.

Montenegro, A. A. A., Abrantes, J. R. C. B., De Lima, J. L. M. P., Singh, V. P. \& Santos, T. E. M. 2013. Impact of mulching on soil and water dynamics under intermittent simulated rainfall. Catena, 109, 139-149.

Ourives, O. E. A., Souza, G. M., Tiritan, C. S. \& Santos, D. H. 2010. Fertilizante orgânico como fonte de fósforo no cultivo inicial de Brachiaria brizantha cv. Marandú. Pesquisa Agropecuária Tropical, 40, 126-132.

Parente, T. L., Lazarini, E., Caioni, S., de Souza, L. G. M., Pivetta, R. S. \& Bossolani, J. W. 2016. Potássio em cobertura no milho e efeito residual na soja em sucessão. Revista Agro@biente, 10,193-200.

Pauletti, V., Barcellos, M., Motta, A. C. V., Serrat, B. M. \& Santos, I. R. 2008. Produtividade de culturas sob diferentes doses de esterco líquido de gado de leite e de adubo mineral. Scientia Agraria, 9, 199-205.

Peña, M. L., Marques, R., Jahnel, M. C. \& Anjos, A. 2005. Respiração microbiana como indicador da qualidade do solo em ecossistema florestal. Floresta, 35, 117-127.

Penteado, S. R. 2007. Adubação orgânica: compostos orgânicos e biofertizantes, Campinas, São Paulo.

Pereira, J. M., Baretta, D., Bini, D., Vasconcellos, R. L. F. \& Cardoso, E. J. B. N. 2013. Relationships between microbial activity and soil physical and chemical properties in native and reforested Araucaria angustifolia forests in the state of São Paulo, Brazil. Revista Brasileira de Ciência do Solo, 37, 572-586.

Pinnow, C., Benin, G., Viola, R., Silva, C. d., Gutkoski, L. C. \& Cassol, L. C. 2013. Qualidade industrial do trigo em resposta à adubação verde e doses de nitrogênio. Bragantia, 72, 20-28.

Prochnow, L. I., Chien, S. H., Taylor, R. W., Carmona, G., Henao, J. \& Dillard, E. F. 2003. Characterization and agronomic evaluation of single superphosphates varying in iron phosphate impurities. Agronomy Journal, 95, 293-302.

Rosim, D. C., Maria, I. C., Lemos, R. \& Silva, Á. P. 2012. Compactação de um latossolo vermelho distroférrico com diferentes quantidades e manejos de palha em superfície. Bragantia, 71, 502-508.

Rosolem, C. A., Santos, F. P., Foloni, J. S. S. \& Calonego, J. C. 2006. Potássio no solo em conseqüência da adubação sobre a palha de milheto e chuva simulada. Pesquisa Agropecuária Brasileira, 41, 1033-1040.

Santos, A. B., Fageria, N. K. \& Zimmermann, F. J. P. 2002. Atributos químicos do solo afetado pelo manejo da água e do fertilizante potássico na cultura de arroz irrigado. Revista Brasileira de Engenharia Agrícola e Ambiental, 6, 12-16.

Santos, D. H., Silva, M. A., Tiritan, C. S., Foloni, J. S. S. \& Echer, F. R. 2011. Qualidade tecnológica da cana-de-açúcar sob adubação com torta de filtro enriquecida com fosfato solúvel. Revista Brasileira de Engenharia Agrícola e Ambiental, 15, 443-449.

Santos, G. A. \& Camargo, F. A. O. 1999. Fundamentos da matéria orgânica do solo: ecossistemas tropicais \& subtropicais. Gênesis, Porto Alegre.

Santos, M. M., Galvão, J. C. C., Silva, I. R., Miranda, G. V. \& Finger, F. L. 2010. Épocas de aplicação de nitrogênio em cobertura na cultura do milho em plantio direto, e alocação do nitrogênio $(15 \mathrm{~N})$ na planta. Revista Brasileira de Ciência do Solo, 34, 1185-1194.

Santos, S. M. C., Antonangelo, J. A., Deus, A. C. F. \& Fernandes, D. M. 2016. Perdas de amônia por volatilização em resposta a adubação nitrogenada do feijoeiro. Revista $d a$ Agricultura Neotropical, 3, 16-20.

Schoninger, E. L., Gatiboni, L. C. \& Ernani, P. R. 2013. Fertilização com fosfato natural e cinética de absorção de fósforo de soja e plantas de cobertura do cerrado Fertilization with rock phosphate and kinetics of phosphorus uptake by soybean and cover crops of Brazilian cerrado soils. Semina: Ciências Agrárias, 34, 95-106.

Severino, L. S., Costa, F. X., Beltrão, N. E. M., Lucena, A. M. A. \& Guimarães, M. M. B. 2004. Mineralização da torta de mamona, esterco bovino e bagaço de cana estimada pela respiração microbiana. Revista de Biologia e Ciências da Terra, 5, 650-655.

Sfredo, G. J. 2008. Soja no Brasil: calagem, adubação e nutrição mineral. Embrapa Soja, LOndrina, Paraná.

Silva, É. M. J., Silva, T. P., Matos, T. E. S., Amorim, I. A., Aquino, A. L. \& Mello, A. H. 
2016. Análise das propriedades químicas de um solo em relação aos diferentes usos e manejos em uma propriedade rural familiar no sudeste do Pará. Cadernos de Agroecologia, 10.

Souza, E. F. C. \& Soratto, R. P. 2006. Efeito de fontes e doses de nitrogênio em cobertura, no milho safrinha, em plantio direto. Revista Brasileira de Milho e Sorgo, 5, 395-405.

Souza, E. R., Assunção Montenegro, A. A., Montenegro, S. M. G. \& Matos, J. d. A. 2011. Temporal stability of soil moisture in irrigated carrot crops in Northeast Brazil. Agricultural Water Management, 99, 26-32.

Stringheta, P. C. 2003. Alimentos orgânicos: produção, tecnologia e certificação. UFV, Viçosa, Minas Gerais.

Taiz, L. \& Zeiger, E. 2009. Fisiologia vegetal. Artmed, Porto Alegre, Brasil.

Tu, C., Louws, F. J., Creamer, N. G., Mueller, J. P., Brownie, C., Fager, K., Bell, M. \& Hu, S. 2006. Responses of soil microbial biomass and $\mathrm{N}$ availability to transition strategies from conventional to organic farming systems. Agriculture, Ecosystems \& Environment, 113, 206-215.
Vasconcellos, P. M. B. 1977. Guia prático para o fazendeiro. NBL Editora, São Paulo.

Veiga, A. D., Pinho, É. V. d. R. V., Veiga, A. D., Pereira, P. H. d. A. R., Oliveira, K. C. \& Pinho, R. G. V. 2010. Influência do potássio e da calagem na composição química, qualidade fisiológica e na atividade enzimática de sementes de soja. Ciência e Agrotecnologia, 34, 953-960.

Wietholter, S., Siqueira, O. J. F., Peruzzzo, G. \& Ben, J. R. 1994. Efeito de fertilizantes minerais e organominerais nos rendimentos de culturas e em fatores de fertilidade do solo. Pesquisa Agropecuária Brasileira, 29, 713-724.

\section{Article History: \\ Received 7 December 2016 \\ Accepted 27 January 2017}

Available on line 3 May 2017

License information: This is an open-access article distributed under the terms of the Creative Commons Attribution License 4.0, which permits unrestricted use, distribution, and reproduction in any medium, provided the original work is properly cited. 